\title{
Community-Based Water Monitoring in Nova Scotia: Solutions for Sustainable Watershed Management
}

\author{
Sarah Weston ${ }^{1,2} \&$ Cathy Conrad ${ }^{1}$ \\ ${ }^{1}$ Department of Geography, Saint Mary’s University, Halifax, Canada \\ ${ }^{2}$ School for Resource and Environmental Studies, Dalhousie University, Halifax, Canada \\ Correspondence: Sarah Weston, Department of Geography, Saint Mary's University, Halifax, Nova Scotia, B3H \\ 3C3, Canada. Tel: 1-902-491-6373. E-mail: Sarah.Weston@smu.ca
}

Received: October 29, 2014 Accepted: November 11, 2014 Online Published: March 3, 2015

doi:10.5539/enrr.v5n2p1

URL: http://dx.doi.org/10.5539/enrr.v5n2p1

\begin{abstract}
Community-based water monitoring (CBWM) has developed significantly over the last decade, both in Nova Scotia and around the world. Concurrently, the literature has thoroughly examined elements of effective CBWM as well as common barriers to its development. Researchers have subsequently recommended ways to increase the capacity of community-based stewardship organizations to ensure that CBWM work is meaningful and is integrated into governmental decision-making and water management.

This paper will review the current state and efficacy of CBWM in Nova Scotia using these recommendations as guidelines. Further, it will examine the role of CURA H2O* in aligning CBWM activities in the Atlantic Region with these guidelines through the implementation of a standardized water quality monitoring training program and an accompanying set of equipment. Additional capacity-building activities led by CURA H2O include participatory research, training workshops, technical support, and the provision of a central database to house data collected through this program. This paper will discuss transferable strengths of this work, and will suggest ways in which developmental barriers can be overcome through adequate financial resources, using an integrated water management model, applying consistent technical standards, maintaining reciprocity with volunteers, and ensuring knowledge and resource-sharing.

*CURA H2O (http://curah2o.com/) is a Community University Research Alliance project funded by the Social Sciences and Humanities Research Council of Canada that is focused on increasing capacity for integrated water monitoring and management in Canada and internationally. It is run by the Community-Based Environmental Monitoring Network at Saint Mary's University in Halifax, Nova Scotia.
\end{abstract}

Keywords: capacity building, community-based monitoring, citizen science, environmental education, environmental management, environmental monitoring, integrated management, watershed organizations

\section{Introduction}

Citizen science has played an increasingly important role in recent decades as the top-down approach to natural resource management has been rejected due to its social, environmental, and economical unsustainability. An alternative approach to top-down management that recognizes community stewards and citizen science programs as valuable partners in management and regulatory decision-making is increasingly recommended in the literature as a best practice in resource management, and the significance of its emerging role highlighted (Conrad, 2006; Hoyer, Wellendorf, Frydenborg, Bartlett, \& Canfield, 2012; Hsu, Malik, Johnson, \& Esty, 2014; Koehler \& Koontz, 2008; Lurie \& Hibbard, 2008). This shift is reflected globally through policy initiatives of the United Nations such as Agenda 21 or the Aarhus Convention which emphasize that "the serious environmental, social, and economic challenges faced by societies worldwide cannot be addressed by public authorities alone" (UNECE, 2008).

Citizen Science is a broad term encompassing many different types of environmental monitoring and observation projects that are conducted by non-governmental organizations and individuals, often in partnership with research institutions and government agencies (Cornell Lab of Ornithology, 2015). Community-based water monitoring (CBWM) is a specific faction of citizen science that has become increasingly sophisticated and widespread, notably in Canada, the United States, Australia, the United Kingdom, the Netherlands, and Southeast Asia (Koehler \& Koontz, 2008). CBWM varies in its nature and approach, ranging from coordinated 
volunteer monitoring programs to larger-scale, complex watershed management partnerships or councils (Deutsch, Lhotka, \& Ruiz-Cordova, 2009; Flitcroft, Dedrick, Smith, Thieman, \& Bolte, 2009; Hoyer et al., 2012; Koehler \& Koontz, 2008; Lurie \& Hibbard, 2008). For the purpose of this article, the term CBWM will refer to both the monitoring and management aspects of community-based water initiatives. CBWM has evolved as an attempt to provide more comprehensive water quality data than would otherwise be available from government resources alone owing to cutbacks that have significantly reduced monitoring capacity at all levels of government (Conrad, 2006; Sharpe \& Conrad, 2006; Mackechnie, Maskell, Norton, \& Roy, 2011; Pollock \& Whitelaw, 2005; Whitelaw, Vaughn, Craig, \& Atkinson, 2003).

The Community-based Environmental Monitoring Network (CBEMN, http://www.envnetwork.smu.ca/), housed in the Geography Department of Saint Mary's University in Halifax, Nova Scotia, has supported the work of local CBWM initiatives as they have evolved over the last decade. The CBEMN continues to provide support in helping to design monitoring protocols, offering skills workshops on topics such as how to design a monitoring program, and loaning monitoring equipment through an Environmental Stewardship Equipment Bank. The CBEMN, through Community-University Research Alliance (CURA) funding from the Social Sciences and Humanities Research Council of Canada, recently launched a major project to address needs commonly expressed by stewardship partners. This project, called CURA H2O (http://curah2o.com/), seeks to standardize data collection at the community level through a training program that includes an online water quality monitoring training course and an accompanying equipment toolkit. This program intends to increase the overall capacity of CBWM organizations and the accuracy of data collected by non-governmental monitors, and is supported by an online database that provides a common location for data storage as well as sharing and analysis tools. By standardizing the set of parameters being collected and the equipment being used, this program allows for data comparability across geographic regions and will help facilitate the integration of stewardship data into water management at the government level. CURA H2O began as a pilot project with approximately 16 participants in Nova Scotia. Combined interest and support from government agencies and other mixed stakeholders has expanded the partnership base currently to 35 monitoring organizations across the Atlantic region, Canada, and internationally. Formal program evaluation and feedback gathered on a regular basis through ongoing engagement with partners in program activities indicates a timely provision of training and resources, and that there has been an enthusiastic uptake of resources by watershed organizations.

In addition to providing equipment and training, CURA $\mathrm{H} 2 \mathrm{O}$ is also conducting an extensive research program with community partners, students, and academic experts in Nova Scotia, Ontario, and Africa. Transferable outcomes of CURA H2O research themes include generating new knowledge (and case-study examples) related to (1) effective community-based water monitoring and management (in Canada and internationally), (2) the improved accuracy of non-governmental data collection through the use of standardized training and equipment with embedded quality assurance and quality control (QA/QC) measures, and (3) community capacity and associated networks. A complete list of research questions based on these themes is available from curah2o.com/research/.

The purpose of this article is to:

i. Compare the current state of CBWM in Nova Scotia with recommendations in the literature on effective community-based monitoring and identify where recommendations have and have not been met.

ii. Examine how CURA H2O can help CBWM in Nova Scotia achieve the goals recommended in the literature. Examples of CBWM in other locations will be studied for successful examples of (a) reliable non-governmental data collection, and (b) data integration into governmental watershed management and regulatory decision-making.

iii. Identify remaining challenges and propose solutions to help achieve long-term provincial water management goals.

\section{Current State of CBWM in Nova Scotia}

Numerous community-based watershed organizations have developed in Nova Scotia over the past decade and currently there are approximately $42 \mathrm{CBWM}$ organizations conducting monitoring, watershed management, and restoration activities (Community-Based Environmental Monitoring Network, 2014). The capacity and skills of these organizations has continued to increase and develop over the last decade, and the CBEMN has responded to ongoing requests for equipment and training. Based on the nature of these requests, there is an observable ebb and flow of stewardship activity in response to environmental pressures in the province such as urban development, mink farming, mining, and golf course construction. However, there is also an observable baseline level of stewardship activity which is independent of changing environmental and governance influences. 
Despite the dedicated work of local community-based organizations towards watershed protection and management, and despite their ability to collect accurate water quality data (Shelton, 2013), opportunities for community input into governmental water management remain limited in Nova Scotia. However, the Water Resource Management Strategy written by Nova Scotia Environment (NSE) in 2010 identifies capacity-building in community monitoring and the overall development of Integrated Water Management (IWM) (management that engages mixed stakeholders including community organizations) as priority areas for action (Nova Scotia Environment, 2012). Although linkages with community organizations are not yet formalized, meaningful and ongoing support of CURA $\mathrm{H} 2 \mathrm{O}$ from governmental partners and technical advisors demonstrates a commitment and openness to move towards IWM and to develop tangible mechanisms to integrate community-based input and water quality data. Based on input from a comprehensive network of mixed-stakeholder partnerships, CURA $\mathrm{H} 2 \mathrm{O}$ itself was developed to facilitate this integration by addressing technical challenges such as data accuracy in CBWM that had been previously expressed by government partners as a barrier to working with community organizations on collaborative watershed management. Ongoing dialogue within this research alliance can serve as the preliminary communication forum for IWM and can help to identify appropriate community input mechanisms to provincial watershed management. Potential mechanisms will be discussed in Section 4 of this paper, along with successful examples of community data integration into governmental decision-making.

\section{CBWM Recommendations in the Literature}

The purpose of this literature search is to compare the state of CBWM in Nova Scotia with recommendations that have been made for CBWM and general efficacy in citizen science over the last decade. This comparison will help to identify universal strengths in the ongoing evolution of CBWM, as well as specific progress and any remaining challenges in CBWM in Nova Scotia. Suggestions will then be provided in Section 4 for overcoming these challenges and for helping to achieve long-term provincial water management goals.

The comprehensive literature review on citizen science conducted by Conrad and Hilchey (2011) was used as a starting point to review sources constituting the main body of literature on this topic. An additional search was then conducted using a variety of keywords found to be used interchangeably with citizen science in the literature and also relevant to CBWM specifically: community-based monitoring, community-based ecological monitoring, community-based watershed management, integrated water resources management, citizen science, and volunteer monitoring. The following electronic databases were used in this search: GreenFILE, ScienceDirect, EBSCO, Web of Science, SpringerLink, and Wiley Online Library. In addition to peer-reviewed articles, relevant sources from grey literature were also reviewed (ex: Florida LAKEWATCH). Excluded were sources that focused on a very specific type of citizen science (ex: community forest management) that posed limited relevance to an examination of CBWM, as well as sources that focused on broader theory from which practical recommendations could not be drawn. Inclusive criteria were sources that discussed practical recommendations on effective general citizen science or CBWM, and those that demonstrated relevance to situational factors in Nova Scotia such as types of monitoring and governance. The resulting 7 key sources and their authors are presented in Table 1 as recommendations for effective citizen science and CBWM.

Among the selected material, five common themes emerged as recommended elements of successful and meaningful citizen science and CBWM: adequate financial resources, integrated water management, technical standards, reciprocity with volunteers, and knowledge and resource-sharing. The remainder of Section 3 will explain further the content of these themes based on their sources listed in Table 1. Section 4 will then examine whether these recommendations are currently being met in Nova Scotia, and how CURA H2O and other stakeholders can help CBWM in Nova Scotia succeed in meeting these recommendations. These themes are transferable and can also be adapted to serve as a practical starting point for developing effective community-based freshwater monitoring programs in any location.

Adequate financial resources: Long-term financial investment in CBWM is recommended as a necessary aspect of effective and consistent water monitoring and management. While CBWM in many cases has become credible and capable of making highly meaningful contributions to water management, many organizations are struggling to access the resources necessary to maintain their monitoring activities. Furthermore, it is not feasible for these organizations to fill gaps in government monitoring that have occurred due to cutbacks without financial or material support to enable this work.

Integrated water management: Integrated water management (IWM) can be defined as "a comprehensive approach to managing water resources, including human activities and their effects on watersheds and ecosystems. It aims to ensure sustainability of water resources and their functions today and into the future" (Nova Scotia Environment, 2013). An integrated management approach generally refers to the inclusion of (1) a 
multi-disciplinary approach in management decisions - for example, taking into account land use activities in addition to managing water quality and quantity, (2) the involvement of relevant stakeholders from across sectors in management and decision-making, and (3) the engagement of multiple levels of government. An integrated water management approach is recommended based on its principles of long-term, equitable, and sustainable water management.

Technical standards: Assuring consistent and high technical standards is recommended as essential to any community-based monitoring where the data will be used in governmental decision-making. Technical training should be incorporated into all aspects of CBWM, and training, data collection methods, and equipment calibration and maintenance should be standardized processes. Quality assurance and quality control measures must ensure consistent and documented procedures. Verifiable, repeatable, simple, and scientifically tested protocols should be used.

Training should require refresher courses and the material itself should be updated periodically. Field procedures and incoming data should be verified by chosen individuals (ex: government technicians, long-term staff at organizations or volunteers who have appropriate technical credentials, scientific experts, etc.) A central data management system should be developed as a storage, analysis, and sharing tool.

Table 1. Summary of Recommendations for effective citizen science and community-based water monitoring and management

Whitelaw, G., Vaughn, H.,
Craig, B., Atkinson, D.
(2003). Establishing the
Canadian Community
Monitoring Network.
Environmental Monitoring
and Assessment, 88,
409-418.
409-418.

1. Secure adequate funding and commitment prior to initiation of monitoring activities

2. Provide feedback to volunteers on how their work is contributing to planning and management

3. Understand participant motivations and skill level and match to the monitoring protocols selected

4. Collaborate with organizations already monitoring through partnership development

5. Utilize simple and scientifically tested methodologies

6. Incorporate training on monitoring protocols, field supervision and verification of monitoring data into the design of community-based monitoring (CBM)

7. Establish a volunteer recognition program

8. Focus on outcomes that serve society through the delivery of policy relevant information

Conrad, C. (2006).

Towards Meaningful Community-Based Ecological Monitoring in Nova Scotia: Where we are versus where we would like to be. Environments 34(1), 25-36.
1. Provide information that is timely, integrated, and non-confrontational

2. Create more opportunities to participate in integrated watershed and resources management

3. Provide financial and material resources need to to community-based groups, via an established mechanism to provide core support for CBM

4. Characterize the information that a spectrum of decision-makers would use and design CBM to deliver it

5. Improve communication and publicize examples, strategies, and opportunities to enhance participation in integrated watershed management, where community groups are a meaningful partner in the process

6. Conduct further research on political and educational strategies to assist CBM in influencing decision-making

7. Think creatively about how to make management experimentation an irresistible opportunity rather than a threat

8. CBM info intended to inform decision-making should be: (i) targeted and relevant to problems, (ii) accessible and understandable, (iii) usable and timely

9. The delivery and communication of CBM info should: (i) suggest a course of action, (ii) allow decision-makers to weigh consequences, (iii) make those involved feel they are in control of the problem

10. Engage politicians and decision-makers

11. Create broader public interest, engagement, and ultimately pressure

12. Make decision-makers better aware of what is being collected and why it is useful 
Sharpe, A., Conrad, C. (2006). Community Based Ecological Monitoring in Nova Scotia: Challenges and Opportunities. Environmental Monitoring and Assessment, 13(3), 305-409.

\section{Establishment of new monitoring programs}

a. Formalize the establishment of the Community-Based Environmental Monitoring Network, with core funding

b. Establish a mentoring program for new groups undertaking monitoring programs, with access to advice on protocols, study design and information management. Provide opportunities for community and all levels of government to meet, network, and build trust; with more dialogue and formal collaboration

2. Ability to collect valid monitoring data

c. Require the incorporation of $\mathrm{QA} / \mathrm{QC}$ procedures into monitoring programs as a condition of funding

3. Ability to share data and conduct analysis between watersheds

d. Develop and adopt scientifically robust, peer-reviewed protocols for water quality parameters

e. Develop a data management structure to allow groups to better manage data internally and share data between groups/agencies

4. Engaging members of the public in ecological monitoring

f. Increase the capacity of groups to engage the public in ecological monitoring, leading to meaningful input into the decision-making structure

\section{Resourcing of Ecological Monitoring}

g. Provide financial and material resources to community-based groups where they fulfill ecological monitoring functions

h. Establish a mechanism to provide core support for CBM, as community groups cannot be expected to bear the full weight of government downloading

6. Opportunities to participate in Integrated Watershed Management

i. Provide examples, strategies and opportunities to enhance participation in integrated watershed management, where community groups are a meaningful partner in the process
Cervoni, L., Biro, A., Beazley, K. (2008).

Implementing Integrated

Water Resources

Management: The

Importance of Cross-Scale

Considerations and Local

Conditions in Ontario and

Nova Scotia. Canadian

Water Resources Journal 33(4), 333-350.

Elements essential to addressing barriers to IWRM:

1. Capacity: Further investment in water management would increase capacity and aid in managing the resource more effectively. Sustained or long-term funding ensures continued and consistent management of water resources. There is inherent value in cost-sharing and/or combined initiatives to more effectively use limited resources and to avoid duplication of effort.

2. Participation and Coordination: Meaningful participation by all stakeholders involved in water resources management is significantly important.

Stakeholders must be willing to make decisions based on an open process that includes appreciation for all mixed interests. Focusing on common goals and objectives is essential during the negotiation process.

3. Scale of Implementation:

a. Effective scales of management need to be identified (ex: watershed boundaries or conservation areas)

b. Management should be coordinated between all levels of government and inclusive of all relevant stakeholders (ex: community, university, industry, etc.)

4. Education: It is important that the public and all stakeholders understand the concept of the watershed and how their actions affect water resources.

Silvertown, J. (2009). A new dawn for citizen science. Trends in Ecology and Evolution. 24, 467-471.

\section{Challenges and Opportunities for Citizen Science:}

1. Data collected by the public must be validated in some way

2. Methods of data collection must be well designed and standardized

3. As many assumptions as possible must be made explicit

4. It is desirable to have a hypothesis in mind, even if it is only a question 
like: "how is x changing" or "how is y distributed"

5. Volunteers must receive feedback on their contribution as a reward for participation

Conrad, C., Hilchey, G. (2011). A review of citizen science and community-based environmental monitoring: issues and opportunities. Environmental Monitoring and Assessment 176, 273-291.

\section{Recommendations for Citizen Science:}

1. A specific focus on increasing the use of data by decision makers and scientists and how that use influences conservation would be particularly valuable

2. Use a framework (see Conrad \& Daoust, 2008)

3. Use positive reinforcement to prevent volunteer dropout

4. Collaborate with other organizations (ex. through a network) to help access information and resources

5. Incorporate training into all aspects of community-based monitoring (CBM)

Areas needing further research:

1. Compare and contrast the success (and situations that induce success) of CBM programs that present sound evidence of citizen scientists influencing positive environmental changes in the local ecosystems they monitor

2. More case studies showing use of CBM data by decision-makers or showing barriers to linkages and how they might be overcome

3. More research comparing the benefits of all types of monitoring and governance (or the situations when it is best to use one governance type over another) could help to improve global CBM

Mackechnie, C., Maskell, L., Norton, L., Roy, D. (2011). The Role of 'Big Society' in monitoring the state of the natural environment. Journal of Environmental Monitoring, $13,2687-2691$.
Key Requirements for Volunteer Monitoring:

1. Quality assurance and standardization of method: measurement process must be calibrated, verifiable, repeatable, and use documented procedures (i.e.: it is quality assured)

2. CBM integrated into decision-making should "encourage systematic, high quality, objective data collection which is consistent within and between areas/countries but aimed at providing information needed for locally relevant concerns." (p. 2691)

Reciprocity with volunteers: Any agencies or organizations that rely on volunteers to collect data should avoid burnout by establishing a volunteer recognition program, or should provide data analysis and feedback on how volunteer activities are contributing to planning and management.

Knowledge and resource-sharing: Long-term, consistent mechanisms should be established to promote collaboration and access to collective information and resources between stakeholders.

\section{CBWM in Nova Scotia, Recommendations in the Literature, and Overcoming Remaining Barriers}

Section 4 will examine how CBWM in Nova Scotia meets the recommendations for effectiveness outlined in Section 3 and how CURA H2O can help CBWM in Nova Scotia meet these recommendations. It will then provide practical examples for overcoming these barriers.

Adequate financial resources: Core funding for stewardship organizations would mean long-term, consistent funding allowing for staff and overhead expenditures. Core funding in this context doesn't usually comprise an entire annual operating budget - supplementary funds are still required. However, core funding increases the likelihood of leveraging additional funds and contributes to the long-term viability of stewardship organizations, especially through the presence of at least one permanent staff person, an office to operate from, and a consistent accumulation of organizational and specialized knowledge.

Unfortunately, as noted by Sharpe \& Conrad in 2006, there is still no core funding available for the majority of CBWM organizations in Nova Scotia (one notable exception is the King's County Lake Monitoring Program administered by the County of Kings). This overall lack of core funding is a significant barrier in capacity building, in maintaining long-term, consistent monitoring programs and data sets, and ultimately in achieving sustainable IWM (Cervoni, Biro, \& Beazley, 2008; Sharpe \& Conrad, 2006). As more stewardship organizations have developed, the competition for available grants has increased, and accordingly the odds of receiving funds have decreased. A competitive environment is created as a result, which discourages organizations from working more closely together when they rely on competing for the same decreasingly available project grants. Alternatively, evenly distributed core or base funding from governments or environmental trust funds 
(independent from and in addition to competitive project grants offered by sponsors) can encourage collaboration and a greater likelihood of achieving stewardship goals and building capacity through knowledge and resource-sharing.

Another limiting factor to organizations without core funding is that the majority of grants offered are project-based and will not allow necessary overhead expenses such as salary to maintain even a single fundamental staff position, pay for electricity or office rental, or support ongoing activities such as water quality monitoring. A key element of establishing a core funding program is to justify the value of the CBWM programs and credibility of the data they produce. The CURA H2O model of a mixed stakeholder alliance connected to a standardized data collection and training program is demonstrating preliminary success in establishing this credibility and in opening formal dialogue across sectors and with local government on how to establish core funding programs.

The Atlantic Coastal Action Program (ACAP) is a community-based program founded by Environment Canada in 1991 to "help Atlantic Canadians restore and sustain local watersheds and adjacent coastal areas" (Environment Canada, 2013). The program serves as a strong example of economic, as well as social and ecological, benefits that can be derived from committed financial investment in CBWM. The same outputs achieved by ACAP organizations between 1997-2002 would have cost Environment Canada twelve times the amount of money if the same outcomes had been pursued through a traditional management approach using government offices and employees (McNeil, Rousseau, \& Hildebrand, 2006; Sharpe \& Conrad, 2006). The economic impact of ACAP in the context of GDP totaled approximately twenty-two million dollars, between 1997-2001, through direct and spin-off economic activities - an amount far greater than the initial six million dollar investment by Environment Canada (McNeil et al., 2006). The ACAP program continues to perform strongly and to deliver on Environment Canada's Strategic Outcomes (Environment Canada, 2013), and is a strong and relevant example that can be used as the basis for more widespread, long-term investment in CBWM in Nova Scotia by municipal, provincial, and federal governments. The Vermont Lay Monitoring Program and the Maine Volunteer Lake Monitoring Program are additional working examples of stewardship organizations that receive core funding from government agencies, conduct long-term water quality monitoring programs, and provide data for use by the contributing agencies (Eastern Charlotte Waterways, 2013). These and other examples can be used to develop a funding model for Nova Scotia.

Integrated water management: IWM is one of the four priority areas for action in Water for Life: Nova Scotia's Water Resource Management Strategy (Nova Scotia Environment, 2012). The presence of numerous and widespread watershed-based community stewardship organizations across Nova Scotia presents a valuable network with which governments could partner to formalize working relationships (Cervoni et al., 2008). The integration of CBWM would support the continued establishment of a comprehensive water quality dataset - a valuable resource from which to make more well-informed management decisions. Currently, the IWM goal of the Water Strategy is being pursued by NSE through two formal committees: the Interdepartmental Water Strategy Implementation Committee and the Nova Scotia Water Advisory Group (NSWAG) (Nova Scotia Environment, 2012). The goal for both committees is to advise implementation of the Water Strategy (Nova Scotia Environment, 2012). While this represents a very promising step forward in IWM in Nova Scotia with representatives from academia, industry, the Nova Scotia Union of Municipalities, and the Federation of Agriculture, avenues for community input remain limited with only one NSWAG member representing the province-wide stewardship community. A more numerous representation of community stewardship perspectives would be necessary in an IWM approach.

NSE and Environment Canada continue to be very supportive of the CBEMN, CURA H2O, and the exploratory movement towards IWM that is being pursued through their work. Extensive technical guidance and expertise has been offered by both agencies as well as by the Halifax Regional Municipality (HRM) over the last decade. Federal, provincial, and municipal staff have provided representation on the CBEMN Advisory Committee, assisted with development of the CURA $\mathrm{H} 2 \mathrm{O}$ water monitoring training course and toolkit, and have provided resources for the development of a common stewardship database that now houses regional data being collected through CURA H2O across all of the Atlantic provinces. Support has also come through participating in mixed stakeholder dialogues on water management in Nova Scotia through CBEMN and CURA management and advisory committees and collaborative working sessions to identify major common goals and research activities.

Ongoing dialogue in the CURA H2O research alliance can serve as the preliminary communication forum for IWM, and further research and discussion is necessary to determine the appropriate formalized process through which to conduct it. A variety of working examples can be used to design an effective IWM model and communication structure in Nova Scotia. One is through watershed councils, which are defined as "assemblies of 
stakeholders who periodically convene to discuss or negotiate the management of streams, rivers, or watersheds" (Leach \& Pelkey, 2001, p. 378). They are commonly composed of environmental organizations, landowners, local individuals, industry, academia, and representatives from multiple levels of government (Flitcroft et al., 2009; Leach \& Pelkey, 2001). Core funding is provided by one or more levels of government, and monitoring, restoration, and protection are common goals that are generally pursued through public education and engagement along with scientific assessment and planning (Flitcroft et al., 2009; Leach \& Pelkey, 2001). Watershed councils could be formed across Nova Scotia by building on existing stewardship organizations and initiatives in each primary watershed - perhaps initially in those identified as priorities for management or risk mitigation. This watershed-based approach would require an overall coordination of management areas and objectives, and also of multiple levels of government and their different agencies. NSE could lead the coordination of this work, and, as in the ACAP program, each council could collaboratively write comprehensive environmental management plans or watershed management plans to guide their work. Alternatively, similar IWM goals could be pursued through the formation of a Watershed Alliance that is made up of a "cooperative association of watershed management groups" (Prince Edward Island Watershed Alliance, 2013). There is no shortage of working examples of specific IWM processes and communication structures to draw from, nor of research-based recommendations for water governance in Nova Scotia that meaningfully engage a broad spectrum of relevant stakeholders and integrated management perspectives in the interest of ecological, economic, and sociological benefits (Cervoni, et al., 2008; Conrad \& Hilchey, 2011; Flitcroft et al., 2009; McNeil, Rousseau, \& Hildebrand, 2006; Sharpe \& Conrad, 2006). Strengths and weaknesses of various management structures have also been explored in the literature (ex: Lurie \& Hibbard, 2008), and this wealth of knowledge should be used to design a meaningful IWM structure appropriate for maximizing the efficiency of water management in Nova Scotia.

Technical standards: It is not uncommon for data collected by volunteers or non-governmental monitors to be used in governmental management and regulatory decision-making (Eastern Charlotte Waterways , 2013; Loperfido, Beyer, Just, \& Schnoor, 2010; Volunteer Monitor, 2004). Despite skepticism surrounding data collected by non-professionals (ex: Gillette, Pondella, Freiwald, Schiff, Caselle, Shuman, \& Weisburg, 2011) it is also possible for this data to be accurate and of high quality, especially when it is collected under specific considerations that are well-researched and have been documented in the literature (Cohn, 2008; Fore, Paulsen, \& O'Laughlin, 2001; Hoyer at al., 2012; Loperfido et al., 2010; Shelton, 2013; Volunteer Monitor, 2004). As presented in Table 1, the elements necessary to ensure high quality data collection in CBWM are:

- Training programs, mandatory 'refresher' courses, and periodic updates to training material

- Standardization of training, data collection, monitoring protocols, and equipment calibration and maintenance

- Use of quality assurance and quality control measures to ensure consistent and documented procedures

- Field procedures and incoming data should be verified by chosen individuals (ex: government technicians, long-term staff at organizations or volunteers who have appropriate technical credentials)

- A central data management system should be used as a tool for storage, analysis, and sharing

Table 2 lists examples of regulatory agencies in Canada and the United States that use non-governmental data in water management through data-sharing arrangements that involve all of the elements listed above. This data is commonly used to identify areas of decreasing water quality, allowing government departments to focus their limited resources on activities such as identifying pollution sources (ex: failed septic systems), enforcing water protection regulations, prioritizing areas that need more in-depth monitoring programs, or assessing trends and concentrations of specific parameters such as nitrogen and phosphorus (Eastern Charlotte Waterways , 2013; Loperfido et al., 2010; Volunteer Monitor, 2004; Volunteer Monitor, 2005). The value and efficiency of community-based data collection is becoming increasingly recognized in practice and in the literature and is considered to be a "robust tool for obtaining credible, cost-effective data" (Hoyer et al., 2012, p. 277). In some cases where governments are unable to keep up with increasing public queries into local water quality, they are able to set up monitoring programs with community partners so that the communities themselves can monitor local water quality and use the data to answer questions and direct their stewardship activities (Hoyer et al., 2012).

Examples listed in Table 2 illustrate that data collection and sharing between community-based organizations and government agencies can be organized in different ways depending on who is leading the initiative. In government-led initiatives, an agency may design and run a volunteer monitoring program, provide training for willing volunteers, choose sampling locations, and design monitoring programs. The Citizen-Lake Monitoring Program run by the Minnesota Pollution Control Agency and Illinois RiverWatch run by the Illinois Department 
of Natural Resources are examples of this approach. A volunteer monitoring program may be established and run by an academic institution, as is the case with Florida LAKEWATCH - a volunteer monitoring program run by the University of Florida (Hoyer et al., 2012). LAKEWATCH receives core funding from the State of Florida, and program staff who are housed in the University design and conduct training and monitoring programs (Florida LAKEWATCH, 2013).

Table 2. Examples of regulatory agencies using non-governmental data in their water management decisions and planning. Sources: Deutsch et al., 2009; Eastern Charlotte Waterways , 2013; Hoyer at al., 2012; Loperfido et al., 2010; McNeil et al., 2006; United States Environmental Protection Agency, 2012; Volunteer Monitor, 2004

\begin{tabular}{|c|c|c|}
\hline Regulatory agency & $\begin{array}{l}\text { Data collection mechanism: } \\
\text { Collaborative monitoring program } \\
\text { (c) or independent partner } \\
\text { organization (i) }\end{array}$ & Data collection led by: \\
\hline $\begin{array}{l}\text { Alabama Department of } \\
\text { Environmental Management }\end{array}$ & Alabama Water Watch (i) & Alabama Water Watch \\
\hline $\begin{array}{l}\text { Florida Department of } \\
\text { Environmental Protection }\end{array}$ & Florida LAKEWATCH (c) & $\begin{array}{l}\text { Coordinated by the University of } \\
\text { Florida }\end{array}$ \\
\hline $\begin{array}{l}\text { Iowa Department of Natural } \\
\text { Resources }\end{array}$ & IOWATER (c) & $\begin{array}{l}\text { Iowa Geological and Water } \\
\text { Survey, Water Monitoring \& } \\
\text { Assessment Section of the } \\
\text { Department of Natural Resources }\end{array}$ \\
\hline $\begin{array}{l}\text { Illinois Department of Natural } \\
\text { Resources }\end{array}$ & Illinois RiverWatch (c) & $\begin{array}{l}\text { Illinois Department of Natural } \\
\text { Resources }\end{array}$ \\
\hline Maine Department of Environment & $\begin{array}{l}\text { Friends of Medomak Watershed } \\
\text { (i) }\end{array}$ & Friends of Medomak Watershed \\
\hline $\begin{array}{l}\text { Maine Department of Natural } \\
\text { Resources }\end{array}$ & $\begin{array}{l}\text { Friends of Medomak Watershed } \\
\text { (i) }\end{array}$ & Friends of Medomak Watershed \\
\hline Minnesota Pollution Control Agency & $\begin{array}{l}\text { Citizen-Lake Monitoring Program } \\
\text { (c) }\end{array}$ & $\begin{array}{l}\text { Minnesota Pollution Control } \\
\text { Agency }\end{array}$ \\
\hline $\begin{array}{l}\text { New Jersey Department of } \\
\text { Environmental Protection }\end{array}$ & Watershed Watch Network (c) & $\begin{array}{l}\text { Government support and } \\
\text { coordination of state-wide } \\
\text { independent community } \\
\text { organizations }\end{array}$ \\
\hline $\begin{array}{l}\text { Pennsylvania Department of } \\
\text { Environmental Protection } \\
\text { (Watershed Support Section, Bureau } \\
\text { of Watershed Management) }\end{array}$ & $\begin{array}{l}\text { Citizens' Volunteer Monitoring } \\
\text { Program (c) }\end{array}$ & $\begin{array}{l}\text { Government support and } \\
\text { coordination of state-wide } \\
\text { independent community } \\
\text { organizations }\end{array}$ \\
\hline $\begin{array}{l}\text { Vermont Department of } \\
\text { Environmental Conservation }\end{array}$ & $\begin{array}{l}\text { Vermont Lay Monitoring Program } \\
\text { (c) }\end{array}$ & $\begin{array}{l}\text { Government support and } \\
\text { coordination of state-wide } \\
\text { independent community } \\
\text { organizations }\end{array}$ \\
\hline $\begin{array}{l}\text { United States Environmental } \\
\text { Protection Agency, Office of Water }\end{array}$ & $\begin{array}{l}\text { EPA's Volunteer Monitoring } \\
\text { Program (c) }\end{array}$ & $\begin{array}{l}\text { Government support and } \\
\text { coordination of nation-wide } \\
\text { independent community } \\
\text { organizations }\end{array}$ \\
\hline $\begin{array}{l}\text { British Columbia Ministry of } \\
\text { Environment }\end{array}$ & $\begin{array}{l}\text { BC Lake Stewardship and } \\
\text { Monitoring Program (c) }\end{array}$ & BC Lake Stewardship Society \\
\hline Environment Canada & $\begin{array}{l}\text { Atlantic Coastal Action Program } \\
\text { (c) }\end{array}$ & $\begin{array}{l}\text { Government support and } \\
\text { coordination of regional } \\
\text { independent community } \\
\text { organizations }\end{array}$ \\
\hline
\end{tabular}

Data sharing can also be facilitated by a government agency providing support and coordination for existing independent CBWM organizations. For example, the New Jersey Department of Environmental Protection (NJ DEP) has appointed a full-time statewide Volunteer Monitoring Coordinator and has defined what data the Department can use and what programs will use it (New Jersey Department of Environmental Protection, 2013). 
For those organizations interested in sharing their data, NJ DEP provides training programs and support from the DEP's Office of Quality Assurance in overseeing the design of quality assurance project plans that meet Department requirements (Volunteer Monitor, 2004). The NJ DEP also provides support and coordination through activities such as the Volunteer Monitoring Summit, through the formation of integrated advisory committees, and by offering project grants to partner organizations (Volunteer Monitor, 2004). Similarly, the Pennsylvania Department of Environmental Protection's Citizens' Volunteer Monitoring Program serves as a support and coordination network for data sharing with independent state CBWM organizations (Volunteer Monitor, 2004). Finally, some data-sharing partnerships are based on the willingness of a regulatory agency to use data collected independently of the agency by a community organization whose data are deemed credible. Data-sharing between the Maine Departments of Environment and Natural Resources and the Friends of the Medomak Watershed are examples of this type of partnership (Volunteer Monitor, 2004).

Currently there are no formal, province-wide water quality data-sharing arrangements in Nova Scotia. However, there is significant potential to develop one based on the presence of numerous and widespread watershed-based community stewardship organizations across the province and on the regional dataset being created through CURA H2O. Examples given in the previous section illustrate that there are different ways to organize data-sharing based on who is leading the initiative or who designs and conducts training. Further dialogue is needed to identify an appropriate form of data-sharing for Nova Scotia that is also embedded in a larger IWM framework to ensure best management practices overall. CURA H2O can continue to facilitate dialogue on this topic between relevant stakeholders and can continue to provide research findings and a foundation of standardized training, equipment, data collection, and storage tools to support this development.

Reciprocity with volunteers: Individual community organizations in Nova Scotia are each responsible for their own relationships with volunteers who are collecting water quality data. In order to avoid volunteer burnout and maintain engagement, there are a variety of ways to establish reciprocity with volunteers and provide feedback on how their activities are contributing to planning and management. One example is the River Guardians Report Card produced by the Clean Annapolis River Project (CARP) in Annapolis Royal. The River Guardians is a volunteer program that monitors water quality on the Annapolis River, and on a regular basis CARP staff produce a report card on the health of the river based on data collected through the Guardians program (Clean Annapolis River Project, 2012). Other examples of volunteer recognition are appreciation events designed to gather volunteers together to review and celebrate their accomplishments or the production of volunteer newsletters which document their achievements (Mersey Tobeatic Research Institute, 2009). As IWM and data-sharing continue to develop on a coordinated provincial scale, the potential for feedback to volunteers through government data analysis should be included in management dialogue. If the data coming in are credible and supplementary, it would require far fewer resources for NSE to provide basic analysis and summary than it would for them to collect the amount of data needed for management on their own.

Knowledge and resource-sharing: Aside from the CBEMN and CURA H2O, there is currently no centralized mechanism or organization in Nova Scotia to facilitate technical knowledge and resource-sharing between stewardship organizations. Mechanisms to promote inter-organizational collaboration and facilitate access to information and resources are a key component of CBEMN and CURA H2O work and are indeed a primary focus of what the CBEMN was founded to do.

The sharing of knowledge, resources and expertise between mixed stakeholders (including community stewardship organizations, established environmental NGOs, Mi'kmaq First Nation communities, public schools, private sector, academia, and government agencies) on the CURA H2O team began with partnerships established by the Community-Based Environmental Monitoring Network. The breadth of these partnerships has increased steadily over the years. The nature of knowledge, resources, and expertise being shared is diverse and ranges from the natural sciences (ex: water monitoring skills, basics of freshwater systems) to policy development (ex: linkages between community-based and governmental resource management) to the social sciences (ex: social capital and network analysis). Additional support for CURA H2O from Environment Canada has allowed this network and its pursuit of common watershed management goals to expand beyond Nova Scotia into New Brunswick, Prince Edward Island, and Newfoundland. Additional project components are also underway in Ontario, the Gambia, and Nepal.

This knowledge and resource exchange occurs primarily through several mechanisms including participatory research, pilot programs for the training course and toolkit, translation and adaptation of the training course, and skills workshops. Workshops are held on topics chosen by partners to strategically develop specific skills and capacity related to water monitoring. A cross-section of partners delivers these workshops which have facilitated meaningful knowledge and resource-sharing between partners from 
across the Maritimes. The productivity of this overall exchange of knowledge and expertise has been heightened by the diverse and complementary range of skill sets, levels, and areas of expertise found among partners. Given the inherent potential for capacity-building in these activities, it is crucial that they continue on a long-term basis as CBWM continues developing in Atlantic Canada. Providing core-funding to the CBEMN would be one way to enhance and maintain these activities, and to establish a mentorship program for less-experienced organizations to work with more established ones. Government agencies could also sponsor an annual regional conference or symposium to strengthen this work.

\section{Discussion and Conclusions}

CBWM capacity in Nova Scotia is steadily increasing. Staff and volunteers of community-led initiatives have developed meaningful water monitoring and management skills over the last decade, and the value and credibility of their work is slowly becoming formally recognized by local government. In reviewing recommendations given in the literature for effective community-based monitoring and CBWM, it is evident that some progress has been made in Nova Scotia that is consistent with these recommendations. However, some key areas need further development in order to maintain and build the momentum.

Firstly, the provision of adequate financial resources or core funding to stewardship organizations on behalf of local governments is a recommended investment in regional water management with potentially high ecological, economic, and social returns. The wealth of knowledge and dedication found in CBWM initiatives across Nova Scotia presents an invaluable opportunity for collaborative watershed management. These widespread and well-developed CBWM initiatives offer government agencies mandated with water quality monitoring a valuable and cost-effective alternative for collecting credible and comprehensive data sets for joint management, protection, and restoration of watersheds (Cervoni, et al., 2008; Conrad \& Hilchey, 2011; Hoyer et al., 2012). Collaborative research on economic models (ex: the establishment of environmental trust funds) should be conducted to identify an appropriate model for long-term support to supplement government funding and project grants.

Further development of IWM is needed to meaningfully engage a greater diversity of stakeholders and develop tangible programs that incorporate non-governmental water quality data into governmental water management. Standardized training programs, methods, and other recommended technical standards for effective CBWM are presented in Table 1 and examples of successful data-sharing and management partnerships are presented in Table 2. Elements of these partnerships, along with lessons learned from the well-developed ACAP program, should be used to design a data-sharing and management structure that meets ecological and stakeholder needs in Nova Scotia.

The water quality monitoring training course and equipment toolkit being piloted by CURA H2O, along with its centralized geodatabase, constitute a strong platform from which to move towards actualized IWM and data-sharing in Nova Scotia. CURA H2O and can also serve as a transferable model that can be adapted and applied in other locations. As the project has developed and become increasingly known since its launch in 2011, inquiries have been received from governments and community organizations across Canada and internationally who are interested in the project's deployment of standardized equipment and training, its quality assurance and quality control elements, and the voluntary participation of 35 partner organizations (with approximately 672 established monitoring locations and 6200 individual observations established over roughly 3 years). This model can be a valuable tool as governments continue to transition from top-down to more de-centralized resource management approaches based on decreasing budgets for resource monitoring.

Beyond the training program and equipment toolkit, the participatory research component of CURA H2O is evaluating this program as it evolves, disseminating research findings and tools to encourage collaboration and transferability of this model, and working to address noted gaps in CBWM literature. While not suggesting an absolute solution for developing CBWM or IWM, components of the CURA H2O project may prove beneficial to a variety of applications. Additionally, the common themes and recommendations presented in Section 3 can serve as a practical starting point for developing effective community-based freshwater monitoring programs in any location.

\section{Acknowledgements}

We would like to acknowledge the Community-Based Environmental Monitoring Network, the Social Sciences and Humanities Research Council of Canada, Saint Mary's University and the Department of Geography, the School for Resource and Environmental Studies at Dalhousie University, Environment Canada, and Nova Scotia Environment for ongoing research support. Thank-you also to the anonymous referees for your time in helping to ensure the overall quality of this research paper. 


\section{References}

Cervoni, L., Biro, A., Beazley, K. (2008). Implementing Integrated Water Resources Management: The Importance of Cross-Scale Considerations and Local Conditions in Ontario and Nova Scotia. Canadian Water Resources Journal, 33(4), 333-350. http://dx.doi.org/10.4296/cwrj3304333

Clean Annapolis River Project. (2012). 2012 River Guardians Report Card. Retrieved from http://www.annapolisriver.ca/publications.php

Cohn, J. P. (2008). Citizen Science: can volunteers do real research? Bioscience, 58(3), 192-197. http://dx.doi.org/10.1641/b580303

Community-Based Environmental Monitoring Network. (2011). Stewardship Groups in Nova Scotia. Retrieved from http://www.envnetwork.smu.ca/welcome.html

Conrad, C. (2006). Towards Meaningful Community-Based Ecological Monitoring in Nova Scotia: Where we are versus where we would like to be. Environments, 34(1), 25-36. http://dx.doi.org/10.1007/s10661-005-9091-7

Conrad, C., \& Daoust, T. (2008). Community-Based Monitoring Frameworks: Increasing the Effectiveness of Environmental Stewardship. Environmental Management, 41, 358-366.

Conrad, C., \& Hilchey, G. (2011). A review of citizen science and community-based environmental monitoring: issues and opportunities. Environmental Monitoring and Assessment, 176, 273-291. http://dx.doi.org/10. 1007/s10661-010-1582-5

Cornell Lab of Ornithology. (2015). Citizen Science Central: What is Citizen Science and PPSR? Retrieved from http://www.birds.cornell.edu/citscitoolkit/about/defining-citizen-science/

Deutsch, W., Lhotka, L., \& Ruiz-Cordova, S. (2009). Group Dynamics and Resource Availability of a Long-Term Volunteer Water-Monitoring Program. Society and Natural Resources, 22, 637-649. http://dx.doi.org/10.1080/08941920802078216

Eastern Charlotte Waterways. (2013). Volunteer Lake Monitoring: A New Brunswick Model. Retrieved from http://www.ecwinc.org/reports/

Environment Canada. (2013). Atlantic Ecosystem Initiatives Year in Review 2009-2010. Retrieved from http://www.ec.gc.ca/iea-aei/default.asp?lang=En\&n=C019BE35-1\#archived

Flitcroft, R. L., Dedrick, D. C., Smith, C. L., Thieman, C. A., \& Bolte, J. P. (2009). Social Infrastructure to Integrate Science and Practice: the Experience of the Long Tom Watershed Council. Ecology and Society, 14(2), 36.

Florida LAKEWATCH. (2013). Florida's Volunteer Water Quality Monitoring Program. Retrieved from http://lakewatch.ifas.ufl.edu/index.htm

Fore, L. S., Paulsen, K., \& O'Laughlin, K. (2001). Assessing the performance of volunteers in monitoring streams. Freshwater Biology, 46(1), 109-123. http://dx.doi.org/10.1111/j.1365-2427.2001.00640.x

Gillette, D., Pondella, D., Freiwald, J., Schiff, K., Caselle, J., Shuman, C., \& Weisburg, S. (2011). Comparing volunteer and professionally collected monitoring data from the rocky subtidal reefs of Southern California, USA. Environmental Monitoring and Assessment, 183, 1-19. http://dx.doi.org/10.1007/s10661-011-2185-5

Hoyer, M. V., Wellendorf, N., Frydenborg, R., Bartlett, D., \& Canfield, D. E. Jr. (2012). A comparison between professionally (Florida Department of Environmental Protection) and volunteer (Florida LAKEWATCH) collected trophic state chemistry data in Florida. Lake and Reservoir Management, 28(4), 277-281. http://dx.doi.org/10.1080/07438141.2012.736016

Hsu, A., Malik, O., Johnson, L., \& Esty, D. C. (2014). Development: Mobilize citizens to track sustainability. Nature, 508, 33-35. http://dx.doi.org/10.1038/508033a

Koehler, B., \& Koontz, T. M. (2008). Citizen Participation in Collaborative Watershed Partnerships. Environmental Management, 41, 143-154. http://dx.doi.org/10.1007/s00267-007-9040-z

Leach, W. D., \& Pelkey, N. W. (2001). Making Watershed Partnerships Work: A Review of the Empirical Literature. Journal of Water Resources Planning and Management, 127(6), 378-385. http://dx.doi.org/10. 1061/(asce)0733-9496(2001)127:6(378)

Loperfido, J. V., Beyer, P., Just, C. L., \& Schnoor, J. L. (2010). Uses and Biases of Volunteer Water Quality Data. Environmental Science and Technology, 44, 7193-7199. http://dx.doi.org/10.1021/es100164c 
Lurie, S., \& Hibbard, M. (2008). Community-Based Natural Resource Management: Ideals and Realities for Oregon Watershed Councils. Society and Natural Resources, 21, 430-440. http://dx.doi.org/10.1080/089419 20801898085

Mackechnie, C., Maskell, L., Norton, L., \& Roy, D. (2011). The Role of 'Big Society' in monitoring the state of the natural environment. Journal of Environmental Monitoring, 13, 2687-2691. http://dx.doi.org/10.1039/ c1em10615e

McNeil, C. T., Rousseau, F. R., \& Hildebrand, L. P. (2006). Community-Based Environmental Management in Atlantic Canada: The Impacts and Spheres of Influence of the Atlantic Coastal Action Program. Environmental Monitoring and Assessment, 113, 367-383.

Mersey Tobeatic Research Institute. (2009). Volunteer Newsletters. Retrieved from http://www.merseytobeatic.ca/ mtri-publications.php

New Jersey Department of Environmental Protection. (2013). Volunteer Monitoring. Retrieved from http://www.state.nj.us/dep/wms/bwqsa/vm/

Nova Scotia Environment. (2012). Water for Life: Nova Scotia's Water Strategy Progress Report March 2012. Retrieved from http://www.gov.ns.ca/nse/water/

Nova Scotia Environment. (2013). Nova Scotia's Water Resources Management Strategy. Retrieved from http://www.gov.ns.ca/nse/water.strategy/

Pollock, R. M., \& Whitelaw, G. S. (2005). Community-Based Monitoring in Support of Local Sustainability, Local Environment. The International Journal of Justice and Sustainability, 10(3), 211-228.

Prince Edward Island Watershed Alliance. (2013). About Us. Retrieved from http://peiwatershedalliance.org/ web/?page_id=2

Sharpe, A., \& Conrad, C. (2006). Community Based Ecological Monitoring in Nova Scotia: Challenges and Opportunities. Environmental Monitoring and Assessment, 13(3), 305-409.

Shelton, A. (2013). The Accuracy of Water Quality Monitoring Data: A Comparison Between Citizen Scientists and Professionals (Unpublished master's thesis). Saint Mary's University, Halifax, Canada.

Silvertown, J. (2009). A new dawn for citizen science. Trends in Ecology and Evolution, 24, 467-471.

The Volunteer Monitor. (2004). Special Topic: Agency Partnerships. The National Newsletter of Volunteer Water Quality Monitoring. U.S. Environmental Protection Agency, 16(1).

The Volunteer Monitor. (2005). Data Documentation and Interpretation. The National Newsletter of Volunteer Water Quality Monitoring. U.S. Environmental Protection Agency, 17(1).

UNECE (United Nations Economic Commission for Europe). (2008). "Vision and Mission" of the Aarhus Convention Strategic Plan, paragraph 4, adopted by the Meeting of the Parties to the Aarhus Convention, in Riga, Latvia, on 13 June 2008. Retrieved from http://www.unece.org/fileadmin/DAM/env/pp/welcome.html

United States Environmental Protection Agency. (2012). Monitoring and Assessing Water Quality - Volunteer Monitoring. Retrieved from http://water.epa.gov/type/rsl/monitoring/index.cfm

Whitelaw, G., Vaughn, H., Craig, B., \& Atkinson, D. (2003). Establishing the Canadian Community Monitoring Network. Environmental Monitoring and Assessment, 88, 409-418.

\section{Copyrights}

Copyright for this article is retained by the author(s), with first publication rights granted to the journal.

This is an open-access article distributed under the terms and conditions of the Creative Commons Attribution license (http://creativecommons.org/licenses/by/3.0/). 